\title{
ON THE USABILITY OF AUGMENTED REALITY DEVICES FOR INTERACTIVE RISK ASSESSMENT
}

\author{
A. LANZOTTI ${ }^{1}$, F. CARBONE ${ }^{1}$, GIUSEPPE DI GIRONIMO ${ }^{1}$, S. PAPA ${ }^{1}$, \\ F. RENNO ${ }^{1}$, A. TARALLO ${ }^{1} \&$ RAFFAELE D'ANGELO ${ }^{2}$ \\ ${ }^{1}$ Fraunhofer JL IDEAS, Department of Industrial Engineering, University Federico II of Naples, Italy. \\ ${ }^{2}$ Inail, Contarp, Area Regionale della Campania, Italy.
}

\begin{abstract}
The use of Augmented Reality (AR) technologies is the new challenge of management models born under the "Industry 4.0" paradigm. The aim of the work is to evaluate the usability of two types of AR devices (tablet and see-through) employed in the training and information activities of workers according to the ISO/IEC 9126 and ISO 9241 standards. Starting from the state of the art, evaluating market and competitors and developing different concepts of interfaces, a dedicated application was programmed and, then, the usability of such devices for the professional figures involved was evaluated through experimental tests. Two reference scenarios were defined, the Department of Industrial Engineering of University of Naples Federico II and INAIL (National Institute for Insurance against Accidents at Work) laboratories, an user interface was designed and developed, as an aid in the drafting of the document for risk evaluation and subsequent training of workers. The activity is part of the IDEE Project (Interactive Design for Ergonomics), born by the collaboration between Joint Lab IDEAS and Contarp-INAIL-Regional Management for Campania. The data analysis allowed to evaluate the goodness of the devices and the degree of satisfaction in their use on the basis of the sample of users who conducted the tests. The use of AR devices produces better results than paperwork in terms of efficiency and effectiveness, but not all devices produce appreciable results in terms of user satisfaction. Although AR technologies are mature, the tasks need to be carefully defined to avoid rejection phenomena. The strong expectation, that they generate in potential users, risks to remain disappointed today for some usability limits found in currently available devices. It is necessary to start testing in pilot applications in various industrial fields in order to capture in time and adequately support this opportunity of innovation in Italy.
\end{abstract}

Keywords: Augmented Reality, Risk assessment, Usability.

\section{INTRODUCTION}

A Risk Assessment Document (DVR) is a document that a company's manager prepares to indicate the path followed for risk assessment, the identification of exposed people, and to indicate solution procedures; it also contains a risk assessment matrix and is drafted by the Responsible of the Prevention and Protection Service of every company. The limits of the current document have been explored, especially with regard to the high cost and timing of staff training and information, and how these can be solved with an interactive DVR (i-DVR), ie a User Interface, visible on electronic devices, enabling view safety information for each environment and machine in real time and only if they can serve, helping to reduce the risk of workplace exposure. So, regarding the design of the i-DVR project criticalities were recorded by commissioners, then provided with appropriate technological solutions, in order to proceed with the software implementation.

The technology employed in the activity is Augmented Reality (AR), defined as an enrichment of human sensory perception by video and audio information, generally manipulated and conveyed electronically, that otherwise would not be perceived with the five senses, overlapping information to reality, which then becomes "augmented"; the state of the art for AR libraries and the main devices today in commerce were studied and analysed, and then 
the characteristics and peculiarities of the devices, chosen for the following tests, were defined [1]. The ones with the best features for the case study, in particular the Project Tango tablet by Google and the Epson Moverio BT-200 smartglasses, were chosen.

\section{USABILITY}

Within the Interactive Design [2], Usability is defined as the ability of the interface to be understood, used and liked by the user in certain conditions and the level in which it can be used by specific users to reach certain objectives with effectiveness, efficiency and satisfaction in carrying out an activity under specific conditions [3]. More specifically, for the ISO 9241 standard, "a product's usability is the degree to which it can be used by specified users to reach specified goals with effectiveness, efficiency and satisfaction in a specified context of use".

Effectiveness is defined as the accuracy and completeness with which users reach specified goals. Efficiency is defined as "the amount of resources spent in relation to the accuracy and completeness with which users reach their goals". Satisfaction is defined as "freedom from discomfort and positive attitude toward product use".

\subsection{Usability of Augmented Reality Devices}

In order to evaluate usability, the AHP (Analytic Hierarchy Process) approach proposed by Saaty and the Multiple Criteria Decision Analysis (MCDA) methodology [4] are used. These techniques allow:

1. The hierarchical decomposition of a problem in multiple levels and factors to simplify it;

2. Assigning a score to the multiple factors considered to allow comparison.

Usability tests were carried out at the CONTARP Campania Region's laboratories of INAIL and at IDEAS laboratories of the University of Naples Federico II, selecting a sample of 30 students and professors to cover the age of the population between 19 and 46 years old. During testing, effectiveness, efficiency and satisfaction for each interface (Paper, Tablet, Glasses) were analysed $[5,6]$.

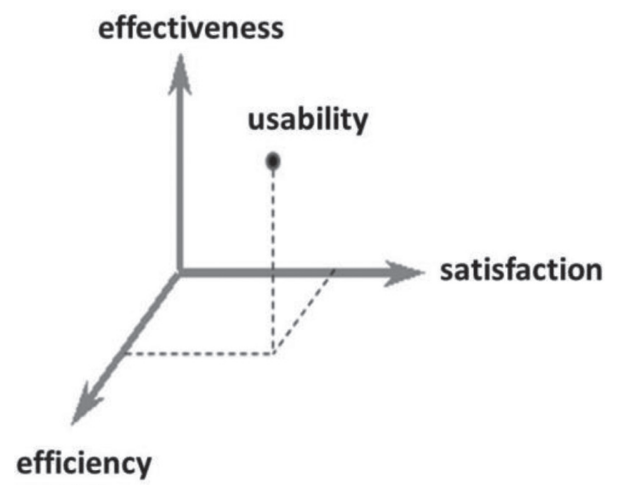

Figure 1: Elements that characterize the usability definition. 

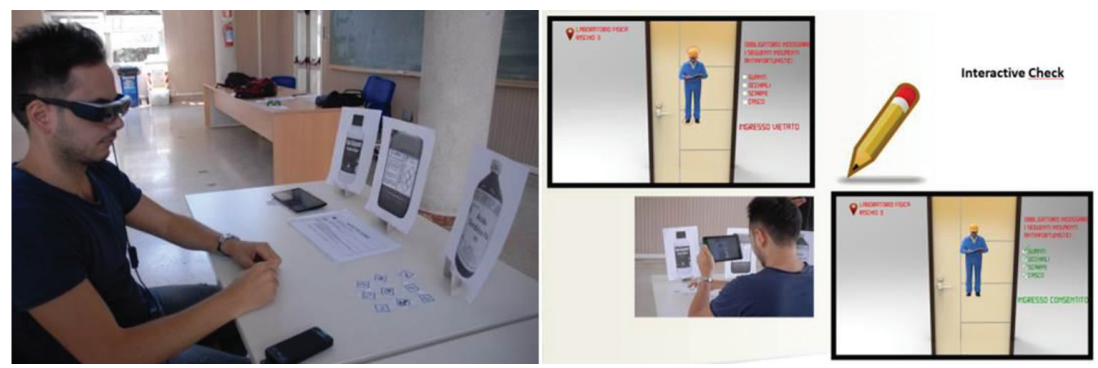

Figure 2: Usability test in the first scenario.

\subsubsection{Principle 1: Efficiency (learning and execution speed)}

Users, monitored and timed, performed three tests of equal difficulty and number of actions using each interface (paper DVR, Project Tango, Epson Moverio).

\subsubsection{Principle 2: Effectiveness (Execution Errors)}

In a scenario representing an emergency condition such as a fire, users made a certain route using a single interface (ten for the paper DVR, ten for Project Tango, and ten for Epson Moverio).

\subsubsection{Principle 3: Satisfaction (tiredness, ergonomics, ease of use)}

User satisfaction was assessed through a subjective evaluation questionnaire [7]. The questionnaire used for the assessments is the System Usability Scale that provides a score based on the Likert scale [8, 9].

At present, it was clear from the testing of technology available in commerce that the Project Tango tablet is considered more usable than the paper DVR, as it is the most effective, efficient and improving user satisfaction.

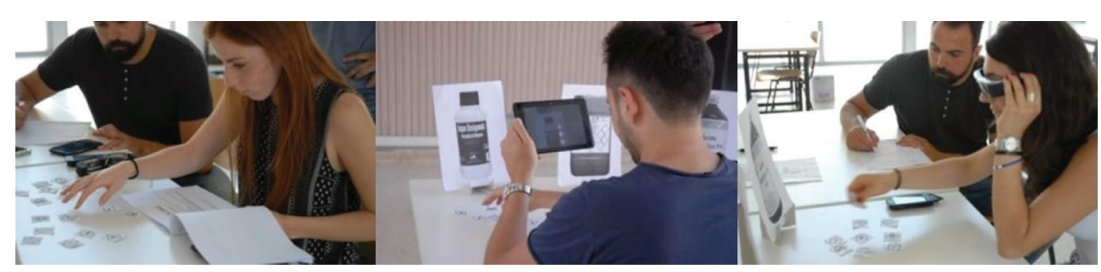

Figure 3: Usability Testing for Efficiency evaluation.

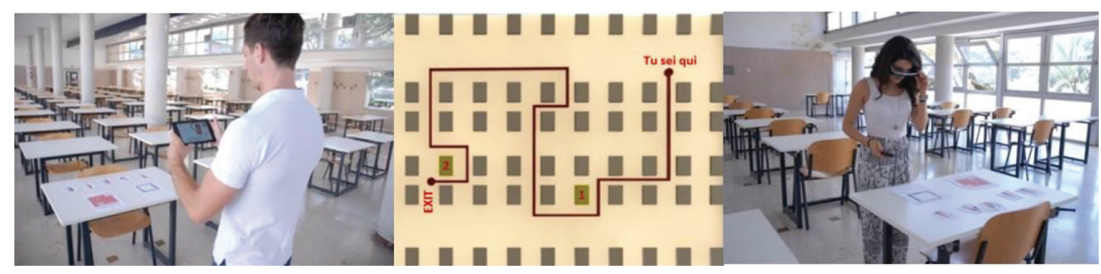

Figure 4: Usability Testing for Effectiveness evaluation. 


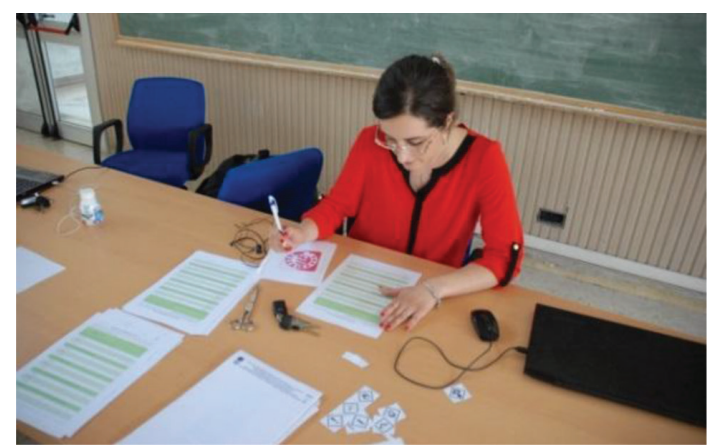

Figure 5: Questionnaire for Satisfaction evaluation.

The experience of using see-through glasses did not meet the total consent of users, giving rise to several aspects to improve such as:

- Image Acquisition Sensor not centred on the device, this gives the user more effort to point the markers, distracting him from what he is looking at.

- Difficulty in perceiving the correct distance and angle between marker and sensor.

- Users with need of eye correction lenses have found particular difficulty in wearing and positioning their glasses to have a correct focus on the images.

These issues, however, can be easily improved with the continued progress of the see-through technologies so that the real strengths can be appreciated, such as having a more immersive experience and the ability to operate hands-free.

\section{TEST IN THE CONTARP CAMPANIA LABORATORIES}

The devices have been used, then, in the INAIL laboratories of CONTARP CAMPANIA, submitting the interactive procedure to the people involved in the tasks for the application tests.

\subsection{Application Test on POROSIMETER}

Entering the lab, the first machine on which the DVR was built was the Porosimeter of the ThermoScientific, Pascal 140 Series model. The mercury intrusion porosimeter uses this type of chemical element, highly toxic, to carry out the analysis; removal of residual mercury in
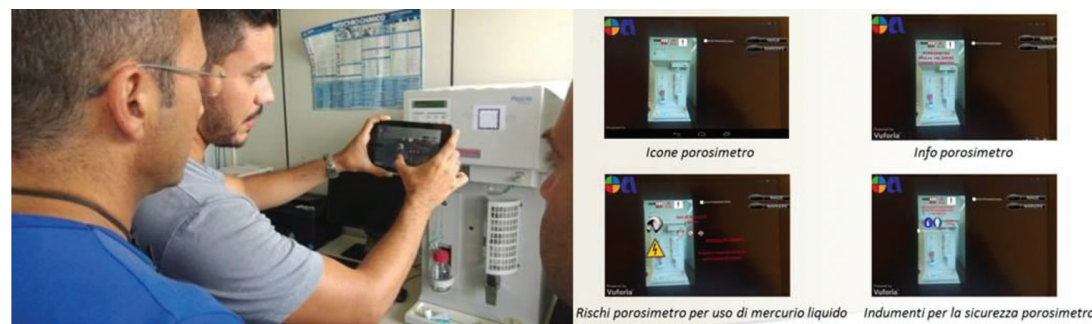

Figure 6: Application Test on POROSIMETER. 

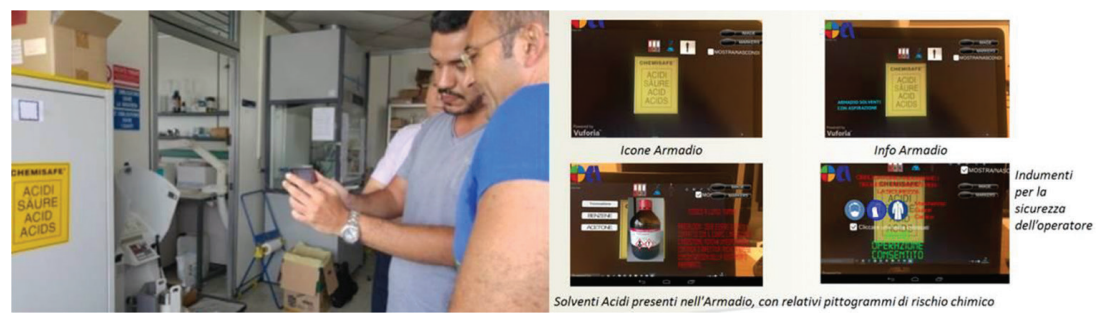

Figure 7: Application Testing on Acid Solvents cabinet.

the porosimeter capillary is carried out with a copper brass-cable treated with nitric acid and previously immersed in mercury, or by connecting the capillary to a vacuum system.

\subsection{Application Testing on Acid Solvents cabinet}

The second "augmented" item is a cabinet containing chemical solvents, in particular acids, used in the various machines. The chemical risk associated with contact with acid substances is high and differentiated; moreover, they are toxic to both the human body and the environment, so the pictograms of the hazard, the risk phrases and the relative precautions to be taken have been highlighted.

\subsection{Use test on CHEMICAL COVER}

The latest machinery encountered in the lab, analysed by the interactive DVR, is the chemical cover, with recirculation, molecular filtration, Strola GS1000 model. It is useful for the protection of personnel exposed to the risk of inhalation of volatile chemicals substances, harmful to health, especially in the case of solvents and toxic fibres. They have been equipped for industrial hygiene analysis, provided with impregnated activated carbon filters, suitable for adsorption of vapours of dangerous substances; in the INAIL laboratory they are fundamental for safety during investigation on asbestos and other carcinogenic substances.
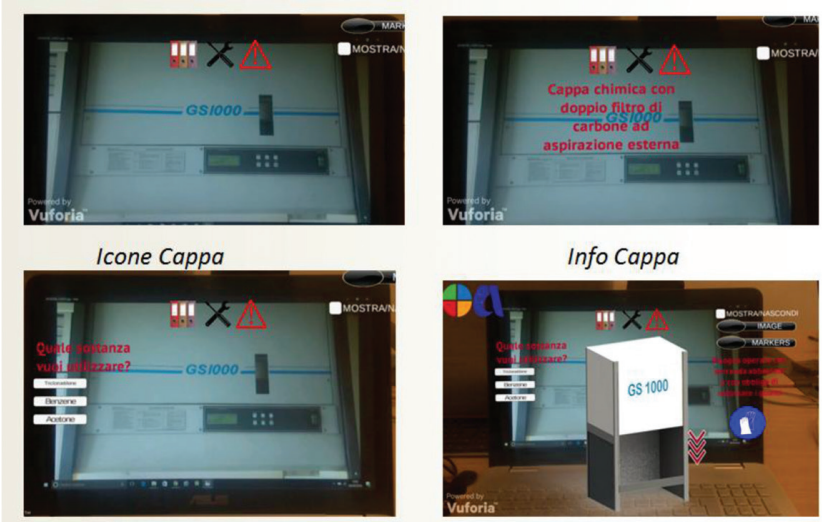

Avvertenze cappa

Uso sostanze tossiche

Figure 8: Use test on CHEMICAL COVER. 


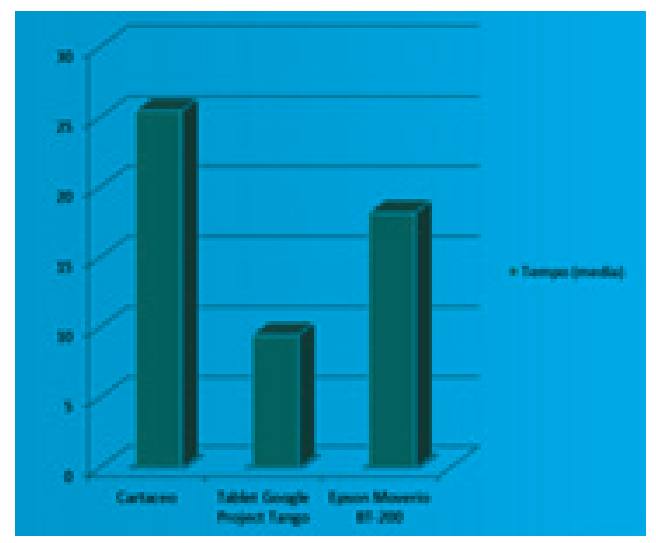

Figure 9: Example of the Efficiency Principle Results.

\section{RESULTS}

The data analysis allowed to evaluate the goodness of the devices and the degree of satisfaction in their use based on the sample of users who conducted the tests. The use of AR devices produces better results than paperwork in terms of efficiency and effectiveness, but not all devices produce appreciable results in terms of user satisfaction. In particular, the use of the tablet is more suitable for users who are not yet accustomed to the use of the viewers and their prolonged use.

\section{CONCLUSIONS}

Although AR technologies are mature, tasks need to be carefully defined for which they can be usefully introduced into workplaces to avoid rejection phenomena. The strong expectation that their use generates in potential users risks to remain disappointed today for some usability limitations found in currently available devices. The evolution of AR technology is so fast that the current criticalities of use will quickly overcome. For this reason testing in pilot applications needs today to be started in various industrial fields to capture in time and adequately support this innovation opportunity in Italy.

\section{REFERENCES}

[1] Di Gironimo, G., Matrone, G., Tarallo, A., Trotta, M. \& Lanzotti, A., A virtual reality approach for usability assessment: case study on a wheelchair-mounted robot manipulator. Engineering with Computers, 29(3), pp. 359-373, 2013. https://doi.org/10.1007/s00366-012-0274-X

[2] Preece, J., Rogers, Y. \& Sharp, H., Interaction Design, beyond human-computer interaction. John Wiley \& Sons, 2002. (Traduzione italiana: “Interaction Design”, Apogeo).

[3] Polillo R., FACILE DA USARE Una moderna introduzione alla ingegneria dell'usabilità, Edizioni Apogeo, 2010.

[4] Figueira, J.,Greco, S. \& Ehrgott, M., Multiple criteria decision analysis: state of the art surveys. Springer, Heidelberg, 2005. 
[5] Patalano, S., Lanzotti, A., Del Giudice, D. M., Vitolo, F. \& Gerbino, S., On the usability assessment of the graphical user interface related to a digital pattern software tool. International Journal on Interactive Design and Manufacturing (IJIDeM), 11(3), pp. 457-467, 2017.

https://doi.org/10.1007/s12008-015-0287-y

[6] Kim, J. \& Han, S., A methodology for developing a usability index of consumer electronic products. International Journal of Industrial Ergonomics, 38(3-4), pp. 333-345, 2008.

https://doi.org/10.1016/j.ergon.2007.12.002

[7] Laugwitz, B., Held, T. \& Schrepp, M., "Construction and Evaluation of a User Experience Questionnaire". Lecture Notes in Computer Science, Holzinger, Andreas, 2008.

[8] Bertram, D., "Likertscales." Retrieved November 2 (2007): 2013.

[9] Brooke, J., SUS-A quick and dirty usability scale. Usability Evaluation in Industry, 189.194, pp. 4-7, 1996. 